Aurelia Journal
(Authentic Research of Global Fisheries Application Journal)
p-ISSN: 0000-0000
e-mail: aurelia.journal@gmail.com

\title{
STRUKTUR DAN UKURAN LAYAK TANGKAP UDANG PUTIH (Penaeus merguiensis) DENGAN ALAT TANGKAP SONDONG DI PERAIRAN DUMAI
}

\section{STRUCTURE AND SIZE DECENT CATCH OF WHITE SHRIMP (Penaeus mergueinsis) CAPTURED SONDONG IN DUMAI WATERS}

\author{
Roma Yuli F Hutapea1 ${ }^{*}$, Tyas Dita Pramesthy ${ }^{1}$, Sri Yenica Roza ${ }^{1}$, Suci Asrina Ikhsan ${ }^{1}$, Ratu Sari \\ Mardiah'1, Ratih Purnama Sari', Shiffa Febyarandika Shalichaty ${ }^{1}$ \\ ${ }_{1}^{1}$ Politeknik Kelautan dan Perikanan Dumai, Dumai, Indonesia \\ *Korespondensi: romafelina@yahoo.co.id (RYF Hutapea) \\ Diterima 29 Juli 2019 - Disetujui 24 September 2019
}

\begin{abstract}
ABSTRAK. Kota Dumai merupakan salah satu wilayah di Riau yang memiiki potensi udang, terutama udang putih. Alat tangkap yang biasa digunaka oleh nelayan untuk menangkap udang adalah sondong.Tingginya aktivitas penangkapan nelayan sondong berdampak pada kelestarian sumber daya udang. Penelitian ini bertujuan untuk menentukan struktur dan ukuran udang; menentukan hubungan panjang dan bobot udang; menentukan nisbah kelamin; serta menentukan ukuran layak tangkap udang. Penelitian ini menggunakan metode purposive sampling. Rata-rata panjang udang jantan dan betina yang tertangkap yaitu 10,4-11,0 cm. Udang jantan yang paling banyak tertangkap berukuran $10 \mathrm{~cm}$ dan udang betina berukuran $12 \mathrm{~cm}$. Pola pertumbuhan udang jantan adalah allometrik negatif, sedangkan pola pertumbuhan udang betina adalah allometrik positif. Udang jantan yang tertangkap sebanyak $79 \%$, sedangkan udang betina sebanyak $21 \%$.
\end{abstract}

KATA KUNCI: Sondong; udang; ukuran; layak; Dumai

ABSTRACT. Dumai is one of the regions in Riau that has potensial of shrimp, especially white shrimp. The fishing gear commonly used by the fishermen to catch shrimp is sondong. The high activity sondong has an impact to shrimp resources. This study aims to determine the structure and size of shrimp; determine the relationship between length and weight of shrimp; determine the sex ratio; and determine the size of shrimp worth catch. This research uses purposive sampling method. The average length of male and female shrimp caught was $10,4-11,0 \mathrm{~cm}$. The most caught male shrimp were $10 \mathrm{~cm}$ and $12 \mathrm{~cm}$ of female shrimp. Male shimp growth pattern was allometric negative, whereas female shimp growth patterns was positive allometrics. Male shrimp caught as much as $79 \%$, which female shrimp as much as $21 \%$.

\section{KEYWORDS: Sondong; shrimp; size; worthy; Dumai}

\section{Pendahuluan}

Kota Dumai merupakan salah satu kota di Provinsi Riau yang memiliki peranan besar dalam sektor perikanan laut. Perairan laut Kota Dumai merupakan perairan dengan dasar pasir berlumpur. Banyaknya lumpur dan padatan tersuspensi diperairan ini disebabkan banyaknya aliran sungai yang bermuara di Selat Rupat. Menurut data Badan Pusat Statistik Kota Dumai (2016), terdapat 6 sungai yang bermuara ke Selat Bengkalis. Dengan banyaknya aliran sungai yang berada di sekitar Kota Dumai dan didukung oleh dua sungai besar yaitu sungai dumai dan sungai mesjid yang mengapit, mengakibatkan perairan di sekitar Kota Dumai subur dengan kandungan mineral-mineral yang terbawa oleh aliran sungai menuju laut. Letaknya yang strategis dan berada di tepi pantai timur Pulau Sumatera menyebabkan Kota Dumai dijadikan sebagai gerbang utama di Sumatera dengan fasilitas pelabuhan terbesar di Provinsi Riau. 
Pangkalan Sesai merupakan salah satu desa yang berada di dalam Kecamatan Dumai Barat. Daerah ini langsung berhadapan dengan Selat Rupat yang berada dalam kawasan Selat Malaka. Kehidupan masyarakat pesisir pangkalan Sesai bermata pencarian sebagai nelayan. Hal ini didukung oleh perairan yang cukup tenang dan arus yang tidak terlalu kuat.

Pertumbuhan populasi manusia yang cepat dan besarnya pengembangan wilayah kota kearah pantai menyebabkan wilayah pantai semakin menyempit. Asley (2005), menyatakan pertambahan penduduk dan pembangunan menyebabkan daya dukung perairan menurun. Masyarakat pesisir kota Dumai rata-rata menggantungkan hidupnya sebagai nelayan. Menurut Arief et al. (2014), kondisi armada perikanan tangkap di kota Dumai masih tergolong kapal motor sederhana seperti gill net, rawai, sondong, dan belat, serta belum menggunakan alat bantu penangkapan. Alat tangkap yang digunakan yaitu: rawai, jaring insang permukaan, jaring kurau (bottom drift gillnet), jaring sondong, dan belat. Salah satu alat tangkap yang dominan digunakan di Pangkalan Sesai adalah alat tangkap jaring sondong. Alat tangkap ini didesain untuk menangkap udang.

Potensi udang di daerah kota Dumai sangat tinggi terutama genus Penaeus, seperti udang putih (Syofyan \& Irwandy, 2016). Salah satu alat tangkap yang banyak digunakan oleh nelayan di Kota Dumai untuk menangkap udang adalah alat tangkap sondong. Meningkatnya penangkapan udang dengan alat tangkap jaring sondong mengakibatkan potensi sumberdaya udang diperairan akan terpengaruh. Berdasarkan data dari Dinas Perikanan Kota Dumai (2016), produksi udang dan udang merah diperairan kota Dumai meningkat dari tahun ke tahun.

Tingginya intensitas penangkapan dengan alat tangkap sondong di perairan kota Dumai memberikan pengaruh terhadap sumberdaya udang di perairan. Intensitas yang tinggi dapat menyebabkan perubahan terhadap aspek biologi, yang mengakibatkan terancamnya kelesatarian populasi udang putih. Oleh karena itu penelitian tentang struktur dan ukuran layak tangkap udang putih perlu dilakukan, untuk menjaga kelestarian sumberdaya udang tersebut. Beberapa penelitian terkait telah dilakukan sebelumnya dan menjadi acuan dalam melaksanakan penelitian.

Penelitian yang relevan dilakukan oleh Wagiyo et al. (2018), tentang aspek biologi, dinamika populasi dan kepadatan stok udang jerbung (Penaeus merguensis) di habitat asuhan estuari Segara Anakan, Cilacap, Wahyuni et al. (2017), membahas beberapa aspek biologi udang putih (Penaeus merguensis) di perairan sebelah utara Brebes dan Tegal, dan Tirtadanu et al. (2017), meneliti sebaran frekuensi panjang, hubungan panjang-berat, tingkat kematangan gonad dan rata-rat ukuran pertama kali matang gonad udang putih (Penaeus merguensis) di perairan Kota Baru, Kalimantan Selatan.

Tujuan dilakukan penelitian ini adalah:

1. Menentukan struktur dan ukuran udang;

2. Menentukan hubungan panjang dan bobot udang;

3. Menentukan Nisbah kelamin;

4. Menentukan ukuran layak tangkap udang.

\section{Bahan dan Metode}

Alat dan bahan yang digunakan dalam penelitian terdapat pada Tabel 1.

Tabel 1. Alat dan Bahan yang digunakan

\begin{tabular}{|c|c|c|}
\hline No & Alat/Bahan & Kegunaan \\
\hline 1 & Udang & Objek/sampel yang digunakan \\
\hline 2 & Timbangan & Alat ukur berat udang \\
\hline 3 & Penggaris & Alat ukur panjang udang \\
\hline 4 & Alat tulis & Mencatat data hasil pengukuran \\
\hline 5 & Kamera & Dokumentasi kegiatan \\
\hline
\end{tabular}


Pengambilan sampel udang putih (Penaeusmerguiensis) dilakukan pada tempat pelelangan ikan (TPI) dimana banyak nelayan yang mendaratkan udang hasil tangkapan jaring sondong. Berdasarkan informasi yang ada di Kota Dumai memiliki 1 TPI yang berada di Pangkalan Sesai. Sampel udang diambil secara sistematik random samping atau proposional yaitu sekitar $10 \%$ dari total hasil tangkapan salah satu perahu pada TPI. Sampel yang didapatkan dipilah-pilah sesuai dengan jenis dan ukurannya. Pengambilan sampel setiap hari selama mulai 15- 30 Desember 2018.

Data yang dikumpulkan pada penelitian ini adalah data primer dan data sekunder. Data primer meliputi informasi jenis udang yang tertangkap, jumlah uadang yang tertangkap, posisi operasi penangkapan udang, waktu operasi penangkapan udang, dan ukuran yang tertangkap. Data primer didapatkan dari PPI Pangkalan Sesai. Sedangkan data sekunder berupa pendukung dari dinas terkait. Pemilihan sampel dilakukan secara sengaja (purposive sampling).

Analisis Data

\section{a. Struktur dan Ukuran Udang}

Perhitungan struktur dan ukuran meliputi panjang maksimal, panjang minimal, panjang ratarata udang, dan panjang yang sering muncul (modus). Dihitung dengan statistik deskriptif dan disajikan dalam bentuk grafik.

b. Hubungan Panjang Bobot berikut:

Menurut Effendy (2002) analisis hubungan panjang berat menggunakan persamaan sebagai

Keterangan :

$$
W=a L^{b}
$$

$$
\begin{aligned}
& W=\text { berat tubuh }(\text { gram }) \\
& L=\text { panjang karapas }(\mathrm{mm}) \\
& a=\text { Intercept } \\
& b=\text { Slope }
\end{aligned}
$$

Bentuk linier dari persamaan tersebut adalah $: \log W=\log a+b \log L$

c. Nisbah Kelamin

Nisbah kelamin dihitung dengan cara membandingkan jumlah udang jantan dengan jumlah udang betina dengan menggunakan uji chi-square (Suparjo, 2005).

$$
X_{2}=\sum\left[(\text { fo-fh })^{2} / \text { fh }\right]
$$

Keterangan :

Fo $=$ Frekuensi udang jantan dan betina yang teramati.

$\mathrm{Fh}=$ Frekuensi harapan, yaitu frekuensi udang jantan ditambah udang betina dibagi dua.

$X_{2}=$ Sebuah nilai bagi peubah acak $x^{2}$ yang sebaran penarikan contohnya menghampiri sebaran.

\section{d. Ukuran Layak Tangkap Udang Putih}

Ukuran udang putih yang layak tangkap didapat dengan cara membandingkan data sampling yang didapat saat penelitian menurut panjang maksimum, panjang minimum, dan panjang rata-rata, dengan data atau referensi ukuran udang putih yang terdapat dipenelitian orang lain, yang dapat digunakan acuan/dasar ukuran udang yang layak ditangkap. 


\section{Hasil dan Pembahasan}

\subsection{Klasifikasi Udang Putih}

Menurut Haliman dan Dian (2006), klasifikasi udang putih (Penaeus merguiensis) adalah sebagai berikut:

$\begin{array}{ll}\text { Kingdom } & \text { : Animalia } \\ \text { Sub kingdom } & \text { : Metazoa } \\ \text { Filum } & \text { : Arthropoda } \\ \text { Subfilum } & \text { : Crustacea } \\ \text { Kelas } & \text { : Malacostraca } \\ \text { Ordo } & \text { : Decapodas } \\ \text { Familia } & \text { : Penaeidae } \\ \text { Genus } & \text { : Penaeus } \\ \text { Spesies } & : \text { Penaeus merguiensis }\end{array}$

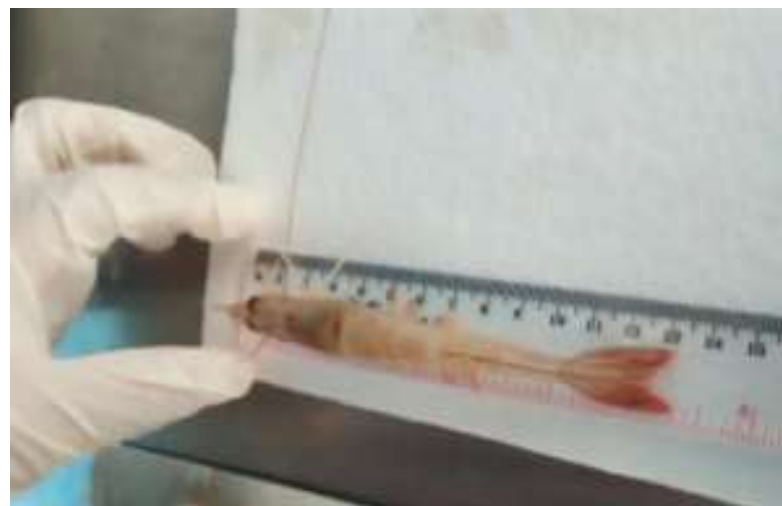

Gambar 1. Udang Putih (Penaeus merguiensis)

Udang putih memiliki tubuh berbuku-buku dan aktivitas berganti kulit luar (eksoskeleton) secara periodik (moulting). Bagian tubuh udang putih sudah mengalami modifikasi sehingga dapat digunakan untuk keperluan makan, bergerak, dan membenamkan diri kedalam lumpur (burrowing), dan memiliki organ sensor, seperti pada antenna dan antenula. Kepala udang putih terdiri dari antena, antenula dan 3 pasang maxilliped. Kepala udang putih juga dilengkapi dengan 3 pasang maxilliped dan 5 pasang kaki berjalan (periopoda). Maxilliped sudah mengalami modifikasi dan berfungsi sebagai organ untuk makan. Pada ujung peripoda beruas-ruas yang berbentuk capit (dactylus). Dactylus ada pada kaki ke1, ke-2, dan ke-3. Abdomen terdiri dari 6 ruas. Pada bagian abdomen terdapat 5 pasang (pleopoda) kaki renang dan sepasang uropods (ekor) yang membentuk kipas bersama-sama telson (ekor).Bentuk rostrum udang putih memanjang, langsing, dan pangkalnya hamper berbentuk segitiga. Uropoda berwarna merah kecoklatan dengan ujungnya kuning kemerah-merahan atau sedikit kebiruan, kulit tipis transparan.

\subsection{Struktur Ukuran Udang}

Berdasarkan hasil penelitian, ukuran maksimum dan minimum udang jantan dan betina yang tertangkap hamper sama. Panjang maksimum udang jantan yang tertangkap yaitu $17,5 \mathrm{~cm}$ sedangkan udang betina $17 \mathrm{~cm}$. Panjang minimum udang jantan yang tertangkap yaitu $6,5 \mathrm{~cm}$ dan panjang minimum udang betina yang tertangkap yaitu $5,5 \mathrm{~cm}$.

Berdasarkan hasil penelitian, ukuran panjang rata-rata udang betina lebih besar dibandingkan udang jantan. Ukuran panjang rata-rata udang betina sebesar $11,0 \mathrm{~cm}$ sedangkan udang jantan sebesar $10,4 \mathrm{~cm}$. Hal tersebut dapat disebabkan oleh faktor biologi pada udang betina, dimana udang betina merupakan udang yang bertelur, sehingga memiliki ukuran tubuh yang lebih besar dibandingkan udang jantan. 
Tabel 2. Struktur Ukuran Panjang Udang Betina dan Udang Jantan

\begin{tabular}{|c|c|c|}
\hline \multirow{2}{*}{ Ukuran } & \multicolumn{2}{|c|}{ Jenis Kelamin } \\
\hline & Jantan & Betina \\
\hline Panjang Maksimum (cm) & 17,5 & 17 \\
\hline Panjang Minimum (cm) & 6,5 & 5,5 \\
\hline Panjang Rata-Rata (cm) & 10,4 & 11,0 \\
\hline
\end{tabular}

Udang yang tertangkap berukuran $5 \mathrm{~cm}$ hingga $17,5 \mathrm{~cm}$. Udang Jantan yang paling banyak tertangkap yaitu udang dengan ukuran panjang $10 \mathrm{~cm}$, sedangkan udang betina yang paling banyak tertangkap berukuran panjang $12 \mathrm{~cm}$. Frekuensi udang jantan dan udang betina yang tertangkap dapat dilihat pada gambar grafik frekuensi hasil tangkapan.

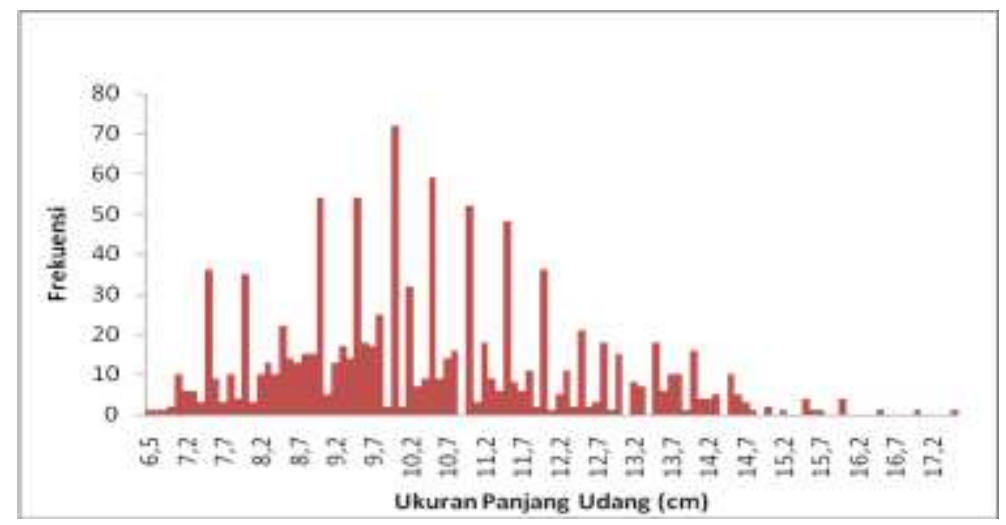

Gambar 2. Grafik Frekuensi Udang Jantan

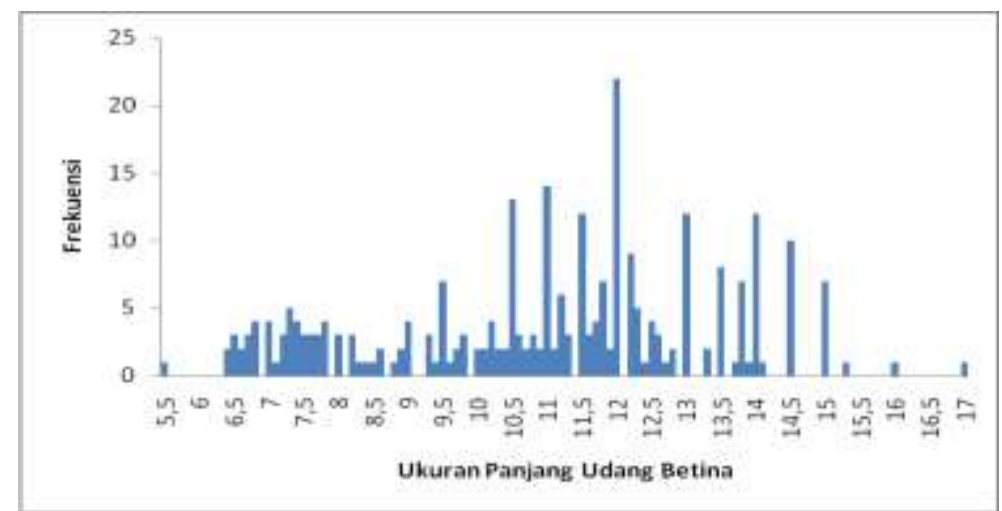

Gambar 3. Grafik frekuensi udang betina

\subsection{Hubungan Panjang Bobot}

Hubungan Panjang dan Bobot Udang dapat dianalisis menggunakan persamaan W= $a^{b}$.Dimanajikanilai $b<3$ maka pola pertumbuhan yaitu allometrik negatif (pertumbuhan bobot lebih besar dibandingkan panjang) dan jika $b>3$ maka pola pertumbuhan yaitu allometrik positif (pertumbuhan panjang lebih cepat dibandingkan pertambahan bobot)

Berdasarkan hasil penelitian, udang jantan memiliki pola pertumbuhan allometrik negatif $(b=2,9594)$ dan pola pertumbuhan udang betina yaitu allometrik positif $(b=3,1468)$. Pada udang jantan pola pertumbuhan bobot lebih cepat dibandingkan pertumbuhan panjang, karena sampel udang jantan yang tertangkap banyak yang telah matang gonad, sedangkan udang betina yang tertangkap rata-rata telah melepaskan telurnya, sehingga pertumbuhan bobot dari udang betina lebih kecil. Hubungan Panjang bobot udang jantan dan betina terdapat pada grafik hubungan panjang bobot. 


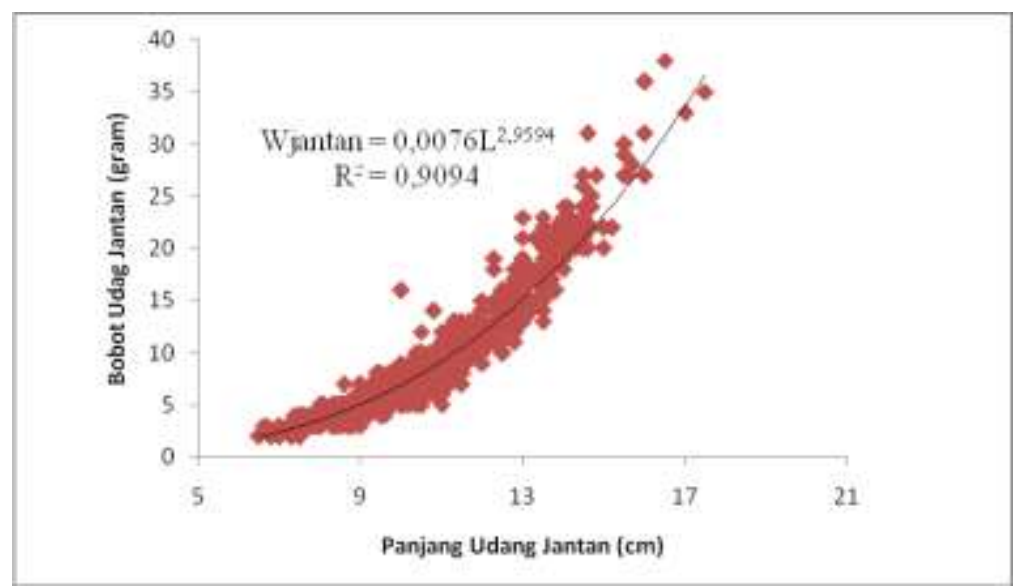

Gambar 4. Grafik Hubungan Panjang dan Bobot Udang Jantan

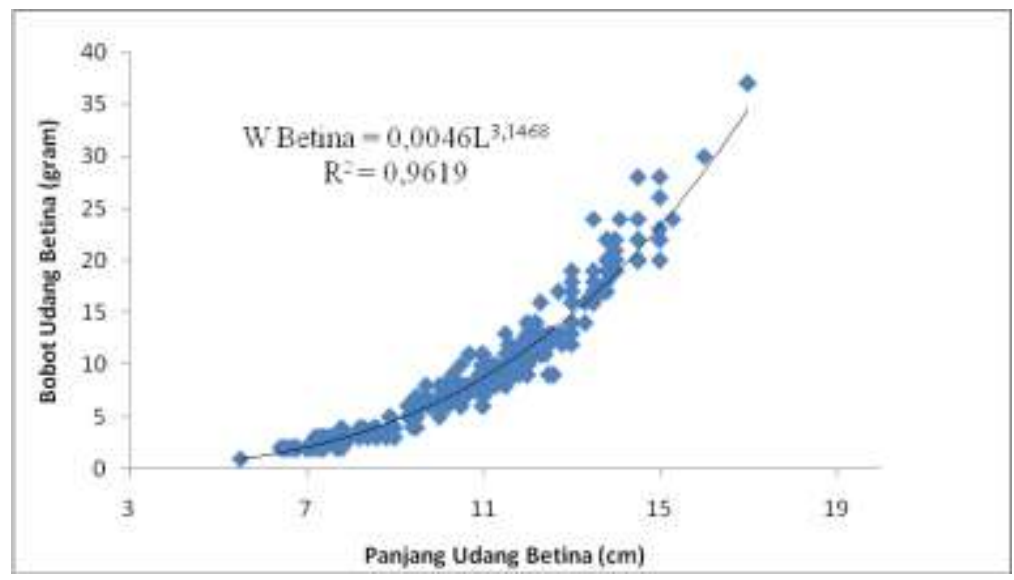

Gambar 5. Grafik Hubungan Panjang dan Bobot Udang Betina

\subsection{Nisbah Kelamin}

Nisbah kelamin merupakan perbandingan antara jumlah udang jantan dan betina yang tertangkap. Berdasarkan hasil penelitian, diketahui bahwa jumlah udang jantan lebih banyak dibandingkan udang betina. Udang jantan yang tertangkap sebesar $79 \%$, sedangkan udang betina yang tertangkap sebesar $21 \%$.

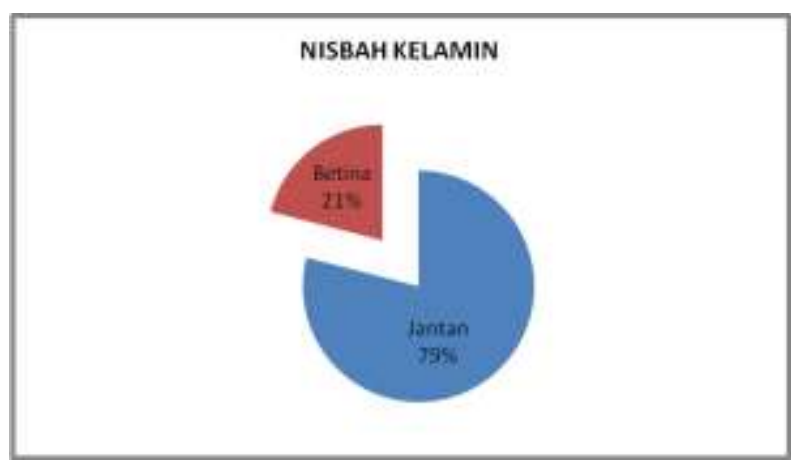

\section{Gambar 6. Nisbah Kelamin antara Udang Jantan dengan Udang Betina}

Hal tersebut dapat dikarenakan, udang betina yang akan melepaskan telurnya telah kembali kelaut atau berada dihabitatnya dikarenakan telah melepaskan telurnya, sedangkan udang jantan berada di muara. Nelayan cenderung melakukan penangkapan di daerah muara, sehingga udang jantan lebih dominan tertangkap dibandingkan udang betina. Penaeus merguiensis, biasa juga disebut 
sebagai udang putih menetaskan telurnya di luar tubuh setelah telur dikeluarkan oleh udang betina. Udang putih adalah jenis udang laut yang habitat aslinya di daerah dasar dengan kedalaman 72 meter. Habitat udang Penaeid usia muda adalah air payau, seperti muara sungai dan pantai. Semakin dewasa udang jenis ini semakin suka hidup di laut. Ukuran udang menunjukkan tingkatan usia. Dalam habitatnya, udang dewasa mencapai umur 1,5 tahun. Pada waktu musim kawin tiba, udang dewasa yang sudah matang telur atau calon spawner berbondong-bondong ketengah laut yang dalamnya sekitar 50 meter untuk melakukan perkawinan. Udang dewasa biasanya berkelompok dan melakukan perkawinan, setelah udang betina berganti cangkang.

\subsection{Ukuran Layak Tangkap Udang Putih}

Ukuran layak tangkap udang putih mengacu pada penelitian Wahyuni et al. (2017) dan berdasarkan data pada sea life base berkisar antara 4,7-12,2 cm. Hasil sampling menunjukkan ukuran yang tertangkap pada kisaran $4,7-12,2 \mathrm{~cm}$ adalah $73,41 \%$ dan $26,58 \%$ udang tidak layak tangkap. Udang jantan yang layak tangkap sebanyak $881(81,35 \%)$ dan $202(18,65 \%)$ udang jantan yang tidak layak tangkap. Sedangkan udang betina layak tangkap sebanyak 199 (69,10\%) dan $89(30,90 \%)$ udang betina yang tidak layak tangkap. Jumlah udang layak tangkap disajikan pada Gambar 7.

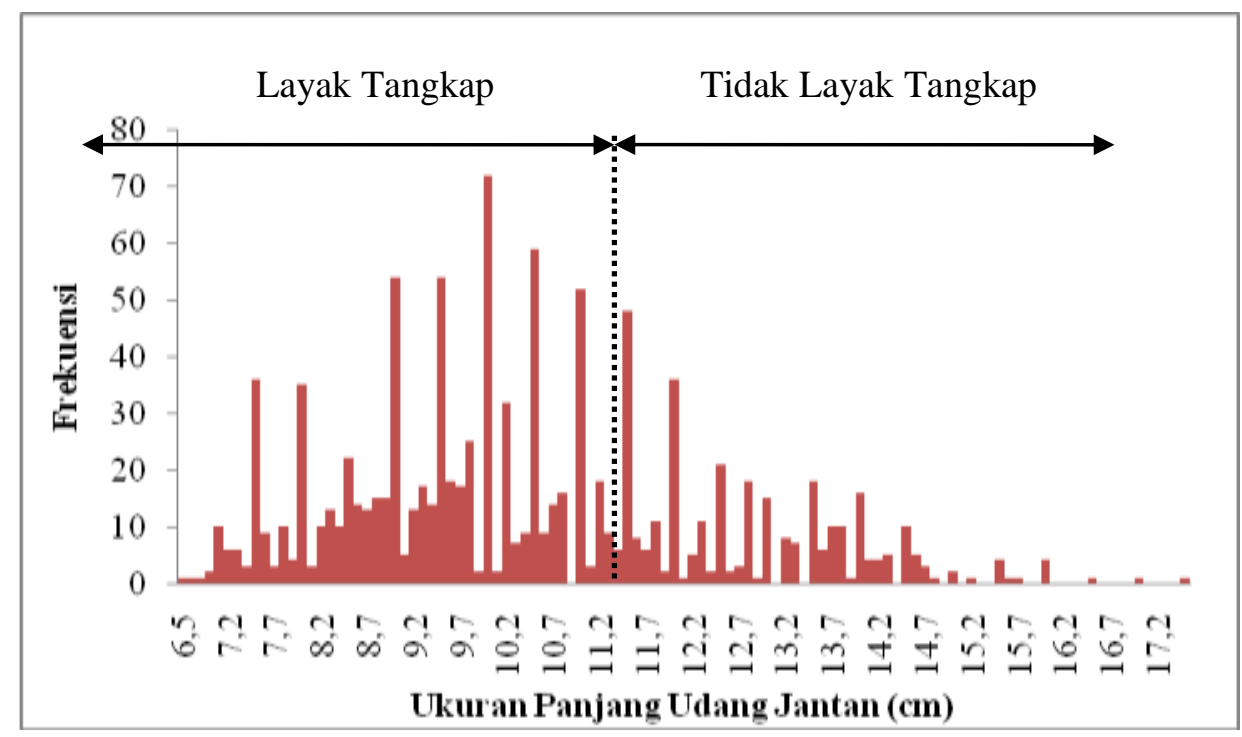

(a)

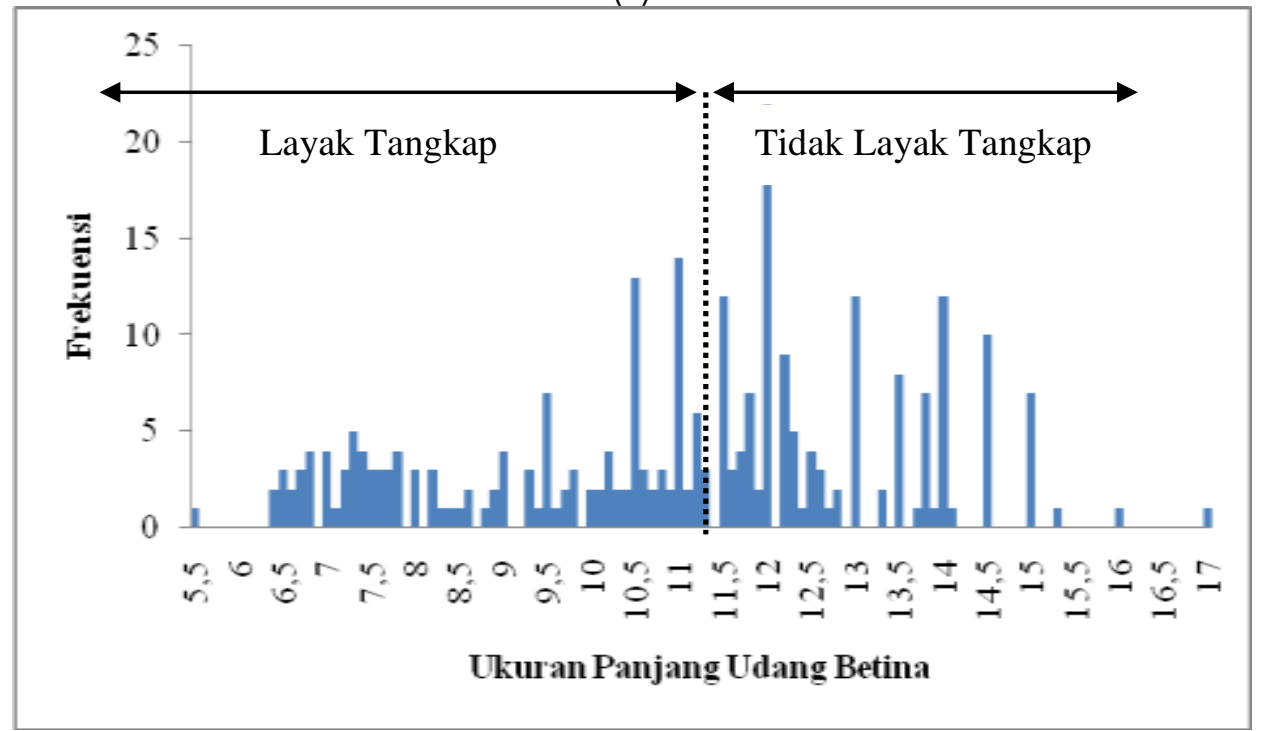

(b)

Gambar 7. Frekuensi Udang Layak Tangkap (a) Udang Jantan (b) Udang Betina 
Pramono et al. (2002), menyebutkan bahwa ukuran udang putih besar yang berhasil tertangkap adalah diatas $10 \mathrm{~cm}$ dan ukuran kecilnya adalah dibawah $7 \mathrm{~cm}$. Hasil penelitian Tenriware (2013) menyebutkan bahwa udang putih yang tertangkap paling banyak di mangrove, dengan kisaran panjang $5-16,8 \mathrm{~cm}$. Hasil penelitian Mahendra et al. (2015), menyebutkan bahwa hasil tangkapan jaring arad untuk udang putih dengan ukuran $7,5-19 \mathrm{~cm}$.

Dari hasil perbandingan beberapa penelitian terdahulu dan hasil penelitian yang telah dilakukan di PPI Pangkalan Sesai mengenai ukuran udang putih layak tangkap, dapat disimpulkan bahwa udang yang tertangkap pada alat tangkap sondong di perairan pantai kota Dumai tergolong dalam ukuran layak tangkap, bila dibandingkan dengan ukuran hasil tangkapan udang dibeberapa wilayah di Indonesia.

\section{Kesimpulan}

Kesimpulan dari penelitian ini adalah

a) Panjang maksimum udang jantan yang tertangkap yaitu $17,5 \mathrm{~cm}$ dan udang betina $17 \mathrm{~cm}$. Panjang minimum udang jantan yang tertangkap yaitu $6,5 \mathrm{~cm}$ dan udang betina yaitu $5,5 \mathrm{~cm}$. Ukuran panjang rata-rata udang betina sebesar $11,0 \mathrm{~cm}$ sedangkan udang jantan sebesar 10,4 $\mathrm{cm}$. Udang yang berhasil ditangkap dan disampling oleh tim merupakan udang dengan ukuran layak tangkap sejumlah $73,41 \%$ dan $26,58 \%$ ukuran tidak layak tangkap.

b) Udang Jantan yang paling banyak tertangkap yaitu udang dengan ukuran panjang $10 \mathrm{~cm}$, sedangkan udang betina yang paling banyak tertangkap berukuran panjang $12 \mathrm{~cm}$.

c) Udang jantan memiliki pola pertumbuhan allometrik negatif $(b=2,9594)$ dan pola pertumbuhan udang betina yaitu allometrik positif $(b=3,1468)$.

d) Udang jantan yang tertangkap sebanyak $79 \%$, sedangkan udang betina yang tertangkap sebanyak $21 \%$.

\section{Daftar Pustaka}

Arief H, Dewi N, Yusri J. (2014). Analisis Potensi Lestari Perikanan Tangkap di Kota Dumai. Indonesian Journal of Agricultural Economics (IJAE) 5 (2): 2014.

Dinas Perikanan Kota Dumai. (2016). Statistik Perikanan Kota Dumai, Dumai.

Effendie, M. I. (2002). Biologi Perikanan. Yayasan Pustaka Nusantara, Yogyakarta

Pramonowibowo, Hartoko A, Ghofar A. (2007). Kepadatan Udang Putih (Penaeus merguensis De Man) di Sekitar Perairan Semarang. Jurnal Pasir Laut 2 (2):18-29.

Mahendra F, Fitri ADP, Asriyanto. (2015). Analisis Hasil Tangkapan Arad Modifikasi (Modified Small Bottom Trawl) di Perairan PPP Tawang Kendal Jawa Tengah. Journal of Fisheries Resources Utilization Management and Technology 4 (1):60-69.

Roach, J. Ashley. (2005). Enhancing maritime security in the Straits of Malacca and Singapore. Journal of International Affairs.

Saputra, S.W. (2009). Dinamika Populasi lkan. Universitas Diponegoro.

Suparjo, M.N. (2005). Potensi Udang Dogol (Metapenaeus ensis) di Kabupaten Kebumen Jawa Tengah.

Syofyan, Irwandy. (2016). Analysis of Sondong Fishing And Development At Kota Dumai. Jurnal Online Mahasiswa (JOM) Bidang Perikanan dan IImu Kelautan.

Tenriware. (2013). Analisis Hasil Tangkapan Kepiting Rajungan (Portunus pelagicus) dan Udang Putih (Penaeus merguiensis) Pada Alat Tangkap Sero di Habitat Berbeda. Jurnal Harpodon Borneo 6 (2):135-142.

Tirtadanu, Surapto, Ali Suman. (2017). Sebaran Frekuensi Panjang, Hubungan Panjang-Berat, Tingkat Kematangan Gonad dan Rata-Rata Ukuran Pertama Kali Matang Gonad Udang Putih (Penaeus merguensis) Di Perairan Kota Baru, Kalimantan Selatan. Bawal 9 (3):145-152. 
Wagiyo Karsuno, Adrian Damora, ARP Pane. (2018). Aspek Biologi, Dinamika Populasi Dan Kepadatan Stok Udang Jerbung (Penaeus merguensis) Di Habitat Asuhan Estuari Segara Anakan, Cilacap. Jurnal Penelitian Perikanan Indonesia 24 (2):127-136.

Wahyuni II, Solichin A, Saputra WS. (2017). Beberapa Aspek Biologi Udang Putih (Penaeus indicus) Di Perairan Sebelah Utara Brebes dan Tegal, Jawa Tengah. Saintek Perikanan 13 (1):38-44. 